\title{
Tracionamento ortodôntico: possíveis consequências nos caninos superiores e dentes adjacentes
}

\section{Parte 1: reabsorção radicular nos incisivos laterais e pré-molares}

Alberto Consolaro*

\begin{abstract}
Alguns profissionais são resistentes a indicar o tracionamento ortodôntico, especialmente dos caninos superiores. Entre as causas mais comuns para restringirem a indicação do tracionamento ortodôntico estão:

1) Reabsorção radicular lateral nos incisivos laterais e nos pré-molares.

2) Reabsorção cervical externa nos caninos tracionados.

3) Anquilose alveolodentária do canino envolvido.

4) Metamorfose cálcica da polpa e necrose pulpar asséptica.

Essas consequências não decorrem primária e especificamente do tracionamento ortodôntico, elas podem ser evitadas se determinados cuidados técnicos forem adotados. Para compreendermos quais são esses cuidados técnicos e como funcionam preventivamente frente às possiveis consequências do tracionamento ortodôntico, devemos nos embasar biologicamente. Esse é o objetivo desta série de trabalhos sobre o tracionamento ortodôntico, especialmente de caninos superiores, e suas possíveis consequências.
\end{abstract}

\section{A formação, estrutura e funções do Folículo Pericoronário}

O folículo pericoronário ocupa o espaço radiolúcido ao redor das coroas de dentes não irrompidos (Fig. 1, 2). Ele está firmemente aderido na superfície da coroa pelo epitélio reduzido do órgão do esmalte (Fig. 3). Esse fino e delicado componente epitelial é sustentado e nutrido por uma espessa camada de tecido conjuntivo com densidade variável de colágeno - ora frouxo, ora até hialinizado. Na parte mais externa dos folículo pericoronários tem-se a sua união ao osso circunjacente (Fig. 2, 3). Em medições de espaços pericoronários nas radiografias periapicais e ortopantomografias, ou panorâmicas, notou-se que a espessura do folículo pericoronário pode chegar a até $5,6 \mathrm{~mm}$ e, ainda assim, apresentar estruturas e organização normais ${ }^{2,4}$ (Fig. 3).

Ao remover o folículo pericoronário e destacá-lo do osso circunjacente, o fragmento tecidual obtido tem a organização de uma película e, por isso, também é conhecido como membrana pericoronária. Ao observar isoladamente o fragmento tecidual representado pelo folículo

* Professor Titular em Patologia da FOB-USP e da Pós-Graduação da FORP-USP. 


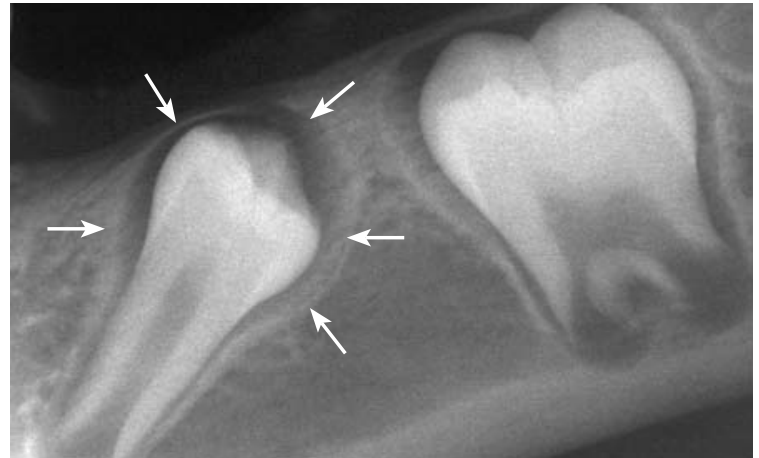

FIGURA 1 - Imagem típica do espaço pericoronário com folículo normal: radiolucidez homogênea, sem pontos radiopacos ou radiolúcidos sobrepostos; limite ósseo nítido, com linha contínua e uniforme (setas); espessura uniforme; contorno regular com medida maior dessa espessura entre 1 e $5,6 \mathrm{~mm}^{2,4}$ pericoronário, temos o aspecto de uma bolsa que continha a coroa dentária e, assim, também é denominado saco pericoronário.

No intermédio das fibras colágenas e dos outros componentes da matriz extracelular do tecido conjuntivo folicular, se distribuem ilhotas e cordões de células epiteliais remanescentes da lâmina dentária (Fig. 3), com número variável de acordo com a idade do paciente ${ }^{2}$.

\section{Como se forma o cordão gubernacular}

A lâmina dentária dá origem aos germes dentários nas partes mais profundas do que será a

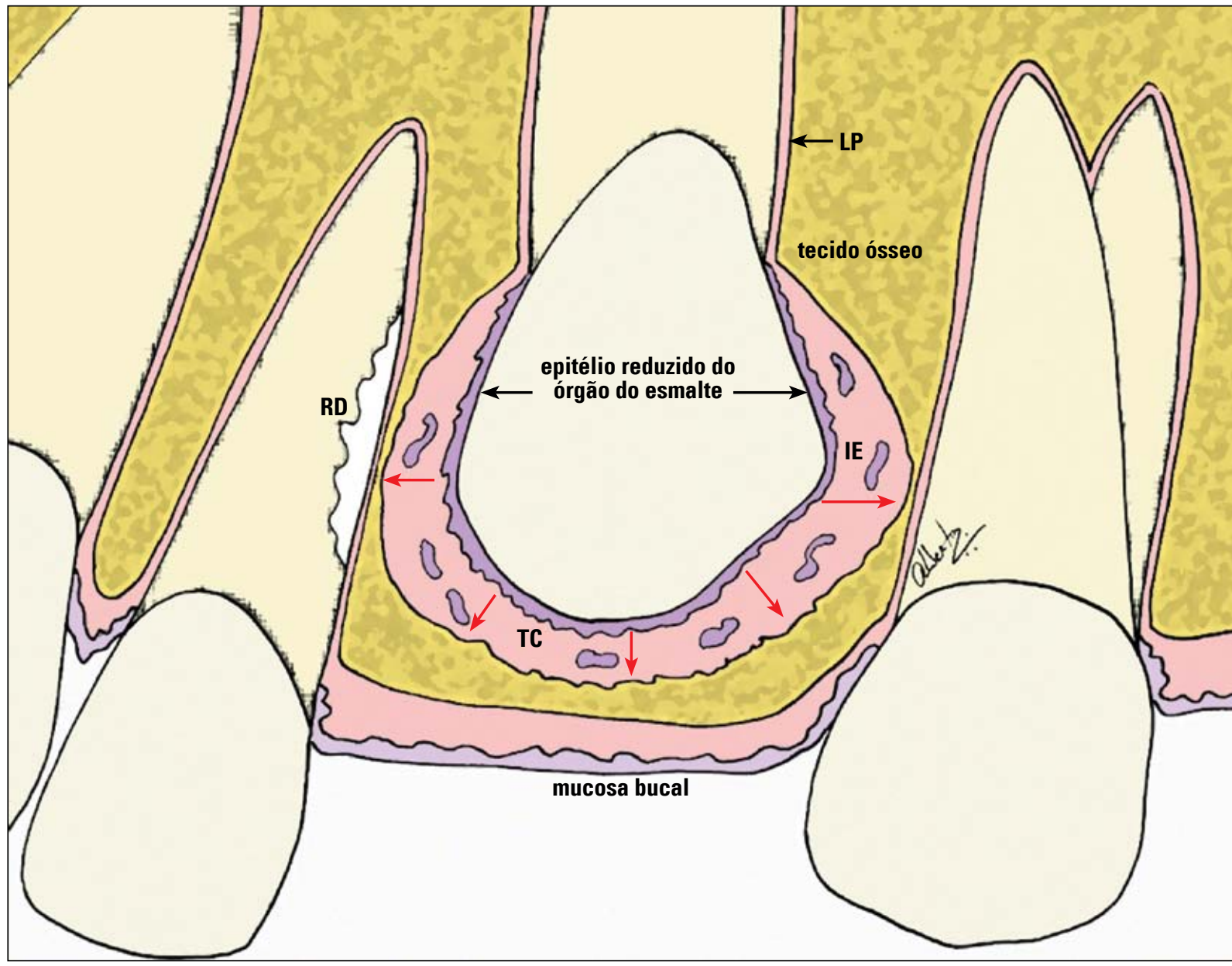

FIGURA 2 - As estruturas epiteliais do folículo pericoronário - como o epitélio reduzido do órgão do esmalte e as ilhotas/cordões epiteliais remanescentes da lâmina dentária (IE) - liberam constantemente EGF ou Fator de Crescimento Epidérmico (setas vermelhas) no tecido conjuntivo (TC). Esse mediador, juntamente com outros ativados a partir de sua ação, induz a reabsorção óssea pericoronária, um fenômeno essencial para que ocorra a erupção dentária. Quando a trajetória do dente não irrompido comprime os vasos do ligamento periodontal (LP) dos dentes vizinhos, sem ou com tracionamento ortodôntico, os cementoblastos morrem no local e a raiz é reabsorvida (RD) para dar lugar ao folículo pericoronário e sua coroa em movimento. 

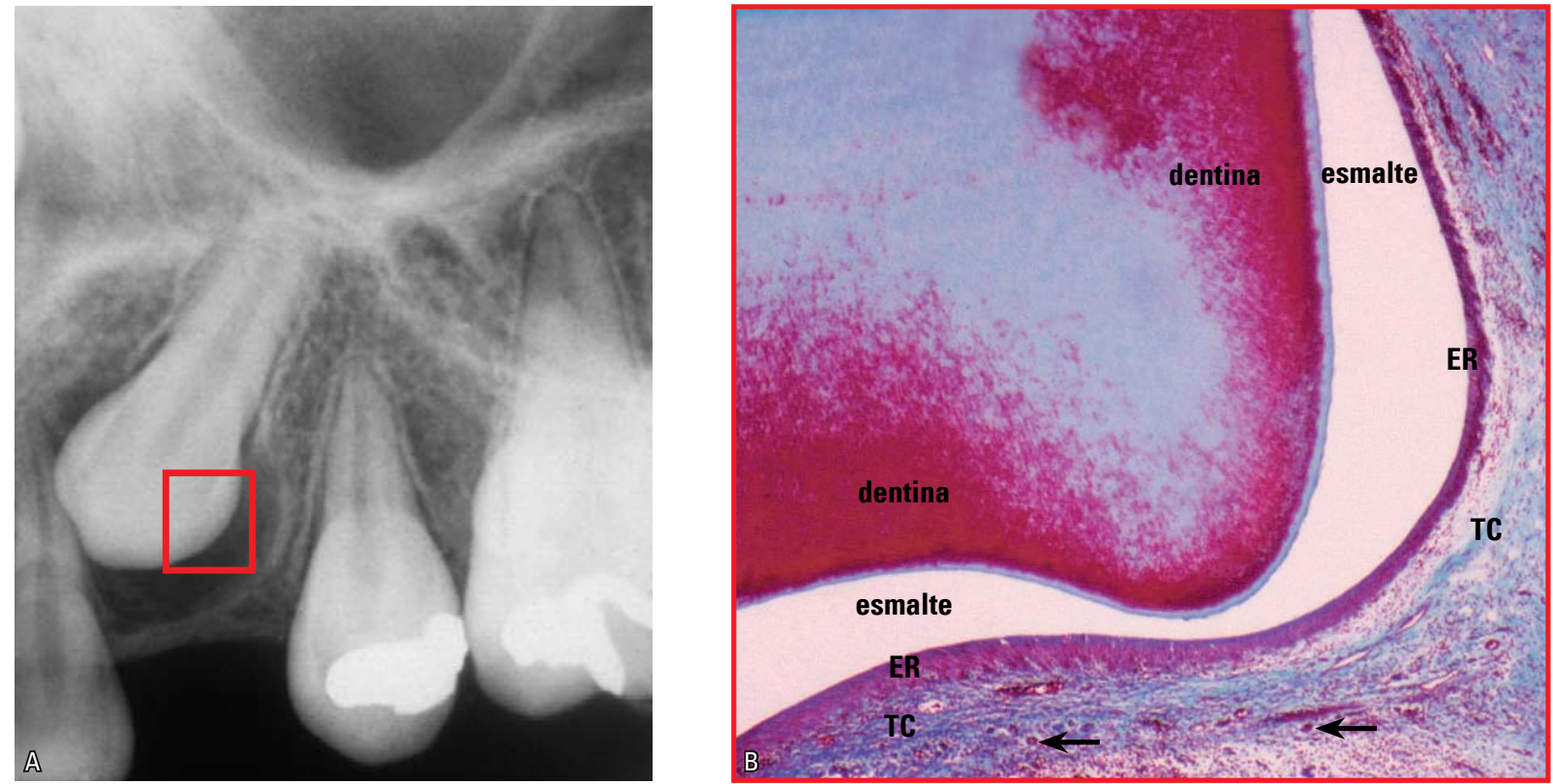

FIGURA 3 - 0 espaço e o folículo pericoronários nos caninos superiores são lateralmente mais bojudos em função da anatomia coronária, como revela-se em A. Sobre o esmalte, os dentes não irrompidos apresentam o epitélio reduzido do órgão do esmalte (ER) firmemente aderido, assim como ilhotas epiteliais remanescentes da lâmina dentária e do cordão gubernacular (setas) distribuídas no tecido conjuntivo (TC) do folículo pericoronário.

futura mandíbula ou maxila. Logo depois, ela se fragmenta por apoptose, mas algumas dessas células persistem de forma programada. As células remanescentes da lâmina dentária organizam-se em forma de ilhotas e cordões epiteliais formando uma verdadeira fila indiana que parte do epitélio reduzido do órgão do esmalte em direção à mucosa bucal. Esse cordão epitelial recebe o nome de gubernaculum dentis, ou cordão gubernacular.

Uma vez estabelecidos os germes dentários e a fragmentação da lâmina dentária, o mesênquima vizinho dá origem ao tecido ósseo. Os germes dentários e o cordão de ilhotas epiteliais são respeitados pelo osso formado ao seu redor para ter lugar a cripta alveolar. Ao redor dos cordões gubernaculares, estabelece-se um canal ósseo delicado que recebe o nome de canal gubernacular.

A função do canal e do cordão gubernaculares está relacionada em direcionar o dente, quando sua coroa estiver completa, em direção ao processo alveolar em sua parte mais oclusal. E, à medida que o dente vai irrompendo em direção à mucosa, o folículo pericoronário vai incorpo- rando em seu tecido conjuntivo as ilhotas e cordões de células epiteliais do cordão gubernacular e vai, cada vez mais, aumentando nessa região o seu componente epitelial (Fig. 3).

\section{A formação das criptas alveolares e do canal gubernacular}

As células epiteliais precisam estar em constante proliferação e síntese, em função de sua constante descamação nos revestimentos cutâneos e mucosos, assim como em função de sua intensa produção de secreções como leite, saliva e lágrimas. Esse constante estímulo à proliferação é providenciado pelas próprias células epiteliais, que liberam para suas vizinhas, via receptores específicos, um mediador denominado EGF ou Fator de Crescimento Epidérmico. Entretanto, nas células ósseas, têm-se receptores para o EGF; mas, nessas, esse mediador estimula a reabsorção óssea. Outros mediadores têm sua ação desencadeada no folículo pericoronário a partir do EGF (Fig. 1), como o TGF-beta, que estimula a formação de clastos, e o CSF-1 e a IL-1, que recrutam seus precursores. 
O tecido ósseo se mantém à distância dos tecidos epiteliais pois o EGF liberado estimula a reabsorção óssea, tal como ocorre com os restos epiteliais de Malassez na manutenção do espaço periodontal sem que o osso chegue à superfície radicular dentária ${ }^{3}$.

$\mathrm{Na}$ formação do osso pelo mesênquima, há uma circunscrição dos germes dentários e estabelecem-se as criptas alveolares e, ao mesmo tempo, o canal gubernacular, pois os germes dentários e as ilhotas e cordões gubernaculares são tecidos epiteliais liberadores de EGF, que constantemente estimula a reabsorção óssea vizinha.

Depois dessa explanação, podemos dizer que:

1. O folículo pericoronário tem um componente epitelial representado pelo epitélio reduzido do órgão do esmalte firmemente aderido à coroa e pelos cordões e ilhotas de células odontogênicas derivadas da lâmina dentária (Fig. 2, 3).

2. O tecido conjuntivo representa o maior volume dos folículos e, fora do espaço pericoronário, tem a forma de uma membrana e/ ou de um saco.

3. O componente epitelial libera EGF continuadamente e, assim, preserva o espaço pericoronário ao estimular a reabsorção óssea, deixando o osso distante do esmalte (Fig. 2).

4. A liberação de EGF e de outros mediadores em cascata o torna essencial para o mecanismo da erupção dentária. As forças derivadas da formação dos dentes e dos vetores de crescimento estimulam uma maior secreção do EGF e promovem uma reabsorção óssea direcionada para a erupção do dente em direção oclusal (Fig. 2).

Quando, experimentalmente, se remove a raiz dentária ${ }^{1}$, mas mantêm-se a coroa e o folículo pericoronário, os dentes irrompem normalmente. Da mesma forma, irrompem quando se remove a coroa e se deixa no local o folículo pericoronário e a raiz dentária. Os dentes artificiais ou réplicas de metal e silicone, quando substituem os dentes não irrompidos mas preserva-se o folículo pericoronário, irrompem da mesma forma. O folículo pericoronário é a estrutura essencial e fundamental da erupção dentária, apesar de por décadas ter-se acreditado que a estrutura indispensável era a raiz dentária.

Critérios de avaliação da imagem do espaço pericoronário: imagem, espessura, contorno e limite

A imagem do espaço pericoronário (Fig. 1, 3, $4,7)$ deve:

a. Ser radiolúcida de forma homogênea, sem pontos radiopacos ou áreas do tipo microlojas radiolúcidas, pois isso pode denotar derivação de tumores odontogênicos.

b. Ter seu limite com o osso vizinho representado por linha radiopaca uniforme e contínua. Caso essa linha esteja interrompida e/ou com imagens do tipo roído de rato, pode representar derivação para cistos e tumores odontogênicos.

c. Ter o contorno caracterizando uma espessura uniforme para o espaço pericoronário, de forma simétrica em relação à coroa dentária. A formação de áreas mais espessas do que outras, em forma de bordados e contornos ondulados, pode caracterizar derivação de cistos e tumores odontogênicos.

d. Ter uma espessura que varia de menos de $1 \mathrm{~mm}$ até $5,6 \mathrm{~mm}^{2,4}$. Além desses limites, deve prevalecer a suspeita de estar presente um cisto dentígero ou outra doença folicular.

$\mathrm{Na}$ avaliação da imagem de um espaço pericoronário, deve-se ressaltar que:

$1^{\circ}$ ) As doenças derivadas do folículo pericoronário podem ser muito pequenas e estar presentes quando o espaço pericoronário ainda apresenta espessuras aparentemente normais.

$2^{\circ}$ ) As alterações derivadas de um folículo pericoronário são eventuais, e percentualmente muito raras, se considerarmos a frequência de dentes não irrompidos presentes nas pessoas. 

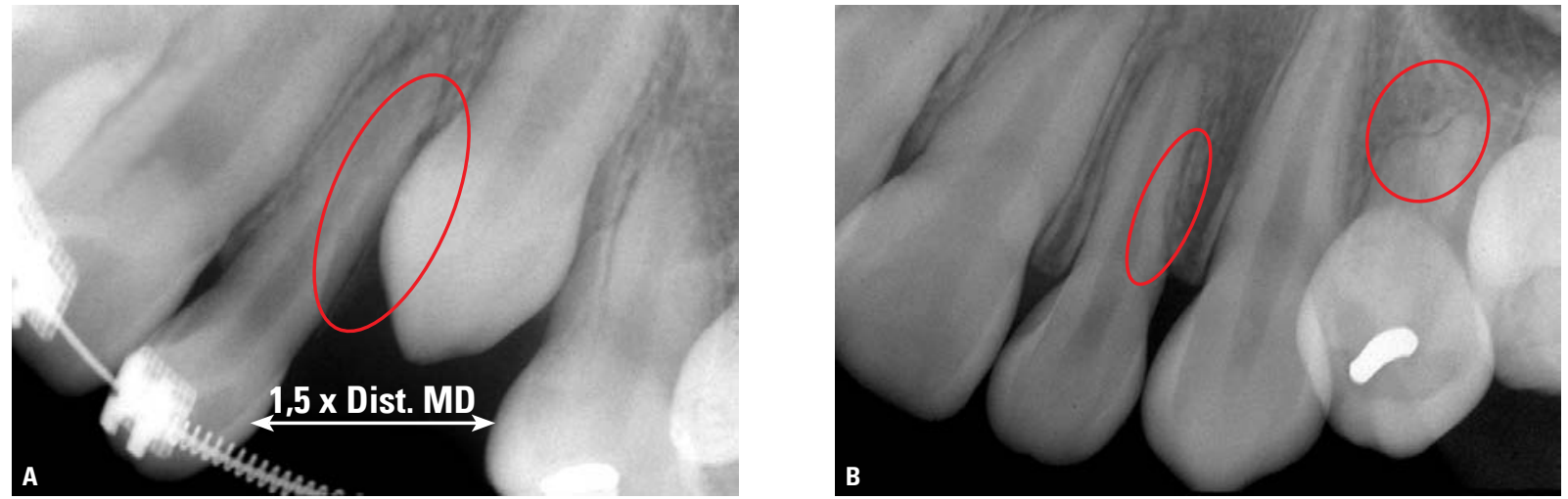

FIGURA 4 - Exemplo de canino superior não irrompido que não atingia o plano oclusal, em $\mathbf{A}$. Com espaço na arcada dentária correspondente a 1,5 vezes a distância mesiodistal da coroa — para que coubesse o folículo pericoronário mais bojudo do canino superior —, 0 dente chegou naturalmente ao seu local na arcada dentária, em B. Mas observa-se que a proximidade prévia do canino superior e seu folículo pericoronário promoveu reabsorção lateral (círculos) nas raízes do incisivo lateral e do primeiro pré-molar.

\section{O conceito de foliculopatias pericoronárias}

As doenças exclusivamente originadas, ou localizadas, nas estruturas do folículo pericoronário podem ser denominadas de foliculopatias pericoronárias. São elas:

* Pericoronarites Aguda e Crônica.

* Cisto Paradentário.

* Cisto Folicular Inflamatório.

* Cisto Dentígero (Fig. 7).

* Cisto de Erupção.

* Folículo Pericoronário Hiperplásico.

No entanto, no folículo pericoronário têm origem muitos outros cistos e tumores odontogênicos, mas não são exclusivos dessa estrutura ou localização. No folículo pericoronário também se originam queratocistos odontogênicos, ameloblastomas, fibromas odontogênicos, odontomas, etc.

\section{O espaço pericoronário dos dentes} não irrompidos e a reabsorção radicular dos dentes vizinhos

O folículo pericoronário é rico em mediadores que estimulam a reabsorção óssea localmente, especialmente o EGF (Fig. 2). Quando vetores do crescimento dos maxilares e as forças eruptivas promovem a proximidade da coroa de um dente não irrompido em relação à raiz de um outro dente já irrompido, ocorre a compressão dos vasos periodontais e a morte de cementoblastos que recobrem a superfície e a protegem da reabsorção (Fig. 5, 6). Dessa forma, teremos superfície radicular exposta e aumento local de mediadores da reabsorção, que estimulam a organização e função de unidades osteorremodeladoras ou BMUs (Fig. 2).

Do ponto de vista imaginológico, o dente não irrompido localizado muito próximo da raiz de um outro dente, e com trajetória ativa em função da erupção e de vetores de crescimento, geralmente induz a reabsorção dentária (Fig. 2, 4, 5, 6). Essa situação é muito comumente observada na região dos caninos em relação aos incisivos laterais superiores (Fig. 4, 5, 6), e nos terceiros molares com a face distal do segundo molar inferior.

A remoção do dente não irrompido promove a regressão do processo e o recobrimento da área reabsorvida por novos cementoblastos, com deposição de nova camada de cemento e reinserção das fibras periodontais. Essa conduta, com frequência, ocorre com os terceiros e segundos molares inferiores. Para isso ocorrer, o ambiente não pode ser contaminado por bactérias.

Nos casos de caninos superiores, os aparelhos ortodônticos e/ou ortopédicos redirecionam a 


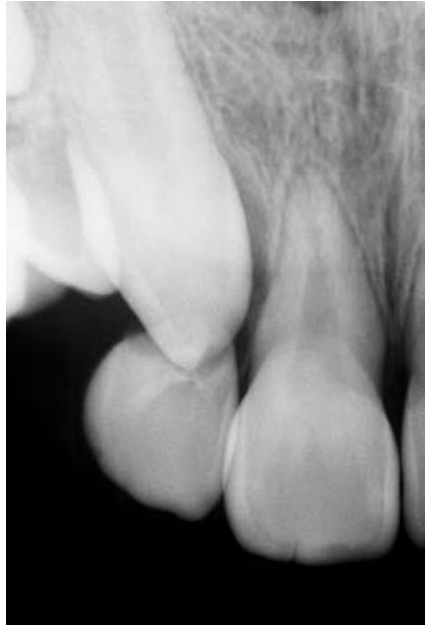

FIGURA 5 - Em alguns casos, a reabsorção dentária promovida pelos dentes não irrompidos, inclusive caninos superiores, nos dentes adjacentes é tardiamente detectada, como ocorreu com esse incisivo lateral superior. Mas, às vezes, pode envolver também os incisivos centrais.
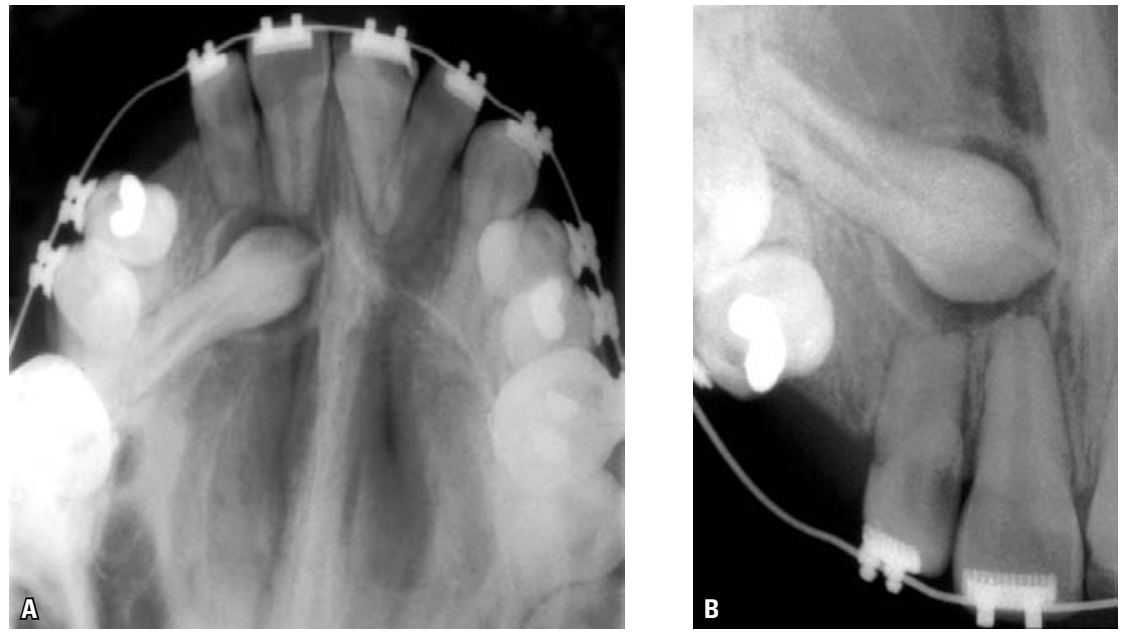

FIGURA 6 - Independentemente da região dentária relacionada à proximidade do folículo pericoronário do dente não irrompido, pode ocorrer reabsorção radicular desde que ocorra compressão dos vasos periodontais e morte dos cementoblastos. A comparação dos lados direito e esquerdo revela que a reabsorção apical tem relação com o canino não irrompido, e não com a movimentação ortodôntica associada. A movimentação do canino não irrompido por tracionamento ortodôntico, quando possível, distancia o folículo pericoronário e, geralmente, cessa a reabsorção radicular e ocorre o reparo da superfície. trajetória eruptiva e/ou também os vetores de crescimento envolvidos, e a reabsorção radicular cessará nos dentes vizinhos, com reparo da superfície por novos cementoblastos e neoformação de cemento (Fig. 4). Essa situação é comum nos caninos em relação aos incisivos laterais superiores.

Uma conduta que deve ser necessariamente adotada para evitar-se a reabsorção dos dentes vizinhos ao dente não irrompido que não será extraído, mas sim tracionado ortodonticamente, implica em aumentar o espaço na arcada dentária para que o mesmo se aloje na área com a sua coroa e, especialmente, com o seu folículo pericoronário. A abertura do espaço elimina a compressão do ligamento periodontal dos dentes vizinhos, e os cementoblastos e cemento voltam a recobrir a raiz desses dentes (Fig. 4, 6). Assim, o folículo pericoronário do dente não irrompido fica mais distante da superfície radicular e seus mediadores não mais atuam como estimuladores da reabsorção dentária, apenas estimulam a reabsorção óssea pericoronária para que a erupção aconteça em sua trajetória desejada.
Tamanho, espessura e forma dos folículos nos caninos superiores em relação aos demais dentes

A espessura e a forma dos folículos propiciam que seus espaços pericoronários sejam mais ou menos uniformes ao contornar suas margens incisais e faces oclusais com as respectivas cúspides (Fig. 1). No entanto, a forma muito específica do canino superior - com suas faces laterais bem convexas e relacionadas a uma verdadeira cúspide na forma de término de sua margem incisal em verdadeiro ângulo agudo - propicia um formato muito específico para o espaço pericoronário (Fig. 3).

O folículo pericoronário do canino superior apresenta-se lateralmente mais bojudo e largo do que nos demais dentes (Fig. 3,6). Nas imagens radiográficas e tomográficas, nota-se claramente que a espessura lateral dos espaços pericoronários dos caninos superiores é maior do que nos demais dentes, especialmente se comparados com os incisivos e mesmo com os pré-molares superiores. 


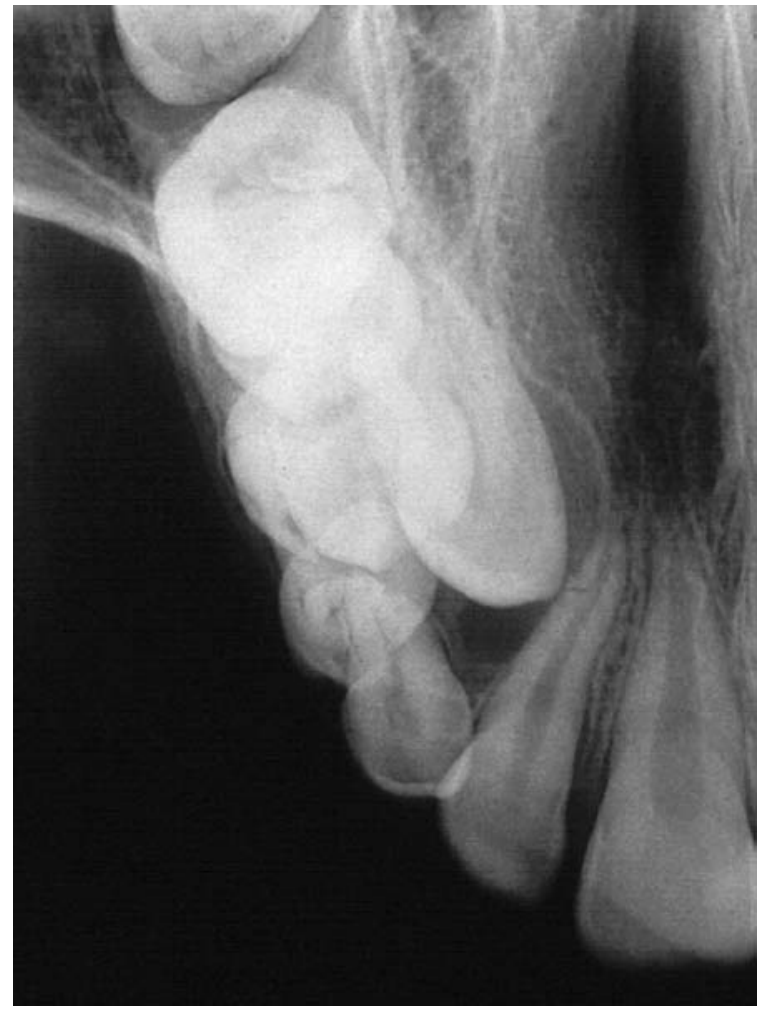

FIGURA 7 - A imagem do espaço pericoronário do canino superior revela a perda dos critérios adotados para se considerar um folículo como normal. A imagem não é radiolúcida homogeneamente e o contorno e a espessura não são uniformes, o que sugere tratar-se de cisto dentígero em fase inicial de estabelecimento, do ponto de vista radiográfico. Essa situação não inviabiliza o tracionamento ortodôntico, caso seja necessário.

O folículo pericoronário dos caninos superiores e seus decorrentes espaços pericoronários são tão bojudos em alguns casos que, ao se somar a prováveis distorções de imagens, oferecem dificuldades para decidir-se entre o diagnóstico de normalidade ou cisto dentígero incipiente (Fig. 3, 6, 7).

$\mathrm{Na}$ avaliação da necessidade de abrir ou não o espaço entre o incisivo lateral e o pré-molar superiores para que o canino se aloje normalmente na arcada dentária, essa característica específica do seu espaço pericoronário mais bojudo lateralmente deve ser considerada.

Essa maior consideração deve ser ressaltada pelo fato do folículo pericoronário não representar apenas um tecido mole que recobre a coroa e que poderia ser simplesmente comprimido em um tracionamento, mas sim por ser o tecido ou órgão responsável pela erupção dentária. Graças à sua grande quantidade de mediadores, o folículo pericoronário estimula a reabsorção óssea pericoronária, promovendo ativamente o movimento dentário em direção oclusal (Fig. 2, 3, 4).

O folículo pericoronário está constituído por tecidos moles e até pode ser fisicamente comprimido entre a coroa do canino e as raízes do incisivo lateral e do pré-molar, mas essa manobra durante o tracionamento pode ter um custo biológico: a reabsorção lateral dessas raízes em menor ou maior grau de comprometimento estrutural (Fig. 4). Junto com a compressão do folículo pericoronário do canino superior ter-se-á compressão dos vasos do ligamento periodontal dos dentes vizinhos e consequente morte dos cementoblastos que protegem essas raízes dos clastos e outros componentes das unidades osteorremodeladoras.

Nas orientações clínicas sobre qual o espaço que deve-se propiciar para tracionar os caninos superiores não irrompidos, sugerimos que se calcule a distância mesiodistal da coroa e multiplique-se essa medida por 1,5. Assim, podemos ter uma maior segurança quanto à integridade lateral das raízes dos dentes vizinhos (Fig. 4).

No entanto, deve-se reconhecer que, nem sempre, a obtenção dessa medida é possível clinicamente em todos os casos. Medidas menores do que essa recomendada podem resultar em sucesso absoluto do tracionamento, sem quaisquer danos aos incisivos laterais e pré-molares superiores, mas os riscos são maiores. A matemática exata nem sempre pode ser sistematicamente aplicada em decisões biológicas. O critério e a medida recomendados representam ponto de partida para a tomada de decisão pertinente a cada caso. Em casos em que possa ser aplicada integralmente, a segurança em preservar as raízes dos dentes vizinhos será maior. 
Nas avaliações dos danos promovidos pela reabsorções radiculares nos incisivos laterais superiores em função da proximidade dos caninos não irrompidos, deve-se sempre ressaltar algumas evidências publicadas ${ }^{5,6}$. Em radiografias periapicais de 3.000 pacientes entre $10 \mathrm{e}$ 15 anos de idade 5 , 12,5\% dos laterais próximos a caninos não irrompidos após o seu tempo normal de erupção apresentaram reabsorções radiculares associadas. Os mesmos casos avaliados em cortes e reconstruções tomográficas revelam que o comprometimento é de $25 \%$. Para avaliarmos com grande precisão os danos promovidos nas raízes dos laterais superiores em casos de tracionamentos de caninos, o melhor método a ser utilizado é representado pela tomografia.

\section{A formação do folículo pericoronário e suas funções}

O órgão do esmalte, em suas fases iniciais, parece um sino ou campânula, com um revestimento conhecido como epitélio interno e externo. Entre um e outro epitélio têm-se duas outras camadas mais espessas de células também epiteliais e conhecidas como retículo estrelado e estrato intermediário. $\mathrm{O}$ órgão do esmalte, à medida que forma esse tecido mineralizado na parte interna dessa campânula, vai se estreitando ou afinando cada vez mais e as quatro camadas epiteliais vão se achatando para formar um único epitélio que fica firmemente aderido à superfície do esmalte e recebe o nome de epitélio reduzido do órgão do esmalte (Fig. 2, 3).

Esse epitélio reduzido do órgão do esmalte, e em decorrência o folículo pericoronário, tem como principais funções:

a) "Esconder" ou proteger o esmalte da reabsorção por parte das células clásticas (Fig. 3).

b) Evitar que o osso se forme diretamente sobre a superfície do esmalte.

c) Participar da erupção dentária ao liberar mediadores próprios dos epitélios, como o EGF. O epitélio reduzido do órgão do esmalte e as ilhotas e cordões epiteliais odontogênicos participam ativamente da reabsorção óssea pericoronária, essencial para que ocorra a erupção dentária com trajetória para a superfície da mucosa alveolar, graças à liberação do EGF (Fig. 2).

d) Constituir o epitélio juncional primário por fusionar-se com a mucosa bucal e permitir que o dente irrompa no meio bucal sem que ocorra a exposição do meio interno do corpo, representado pelo tecido conjuntivo gengival, ao meio bucal altamente contaminado.

\section{Consideração Final}

Entre as consequências possíveis do tracionamento de caninos superiores não irrompidos se enquadram as reabsorções radiculares dos incisivos laterais e pré-molares superiores (Fig. 4, 5, 6). No planejamento de tratamentos de caninos não irrompidos, deve-se considerar a espessura do folículo pericoronário quando se providenciar um alargamento do seu espaço na arcada dentária, visando sua erupção normal ou seu tracionamento ortodôntico. A compressão lateral do folículo pericoronário, durante a erupção com ou sem tracionamento dos caninos, contra as raízes dos incisivos laterais e/ou dos pré-molares pode promover reabsorções nesses dentes, pois haverá compressão dos vasos periodontais e morte dos cementoblastos.

No planejamento do espaço a ser obtido na arcada dentária para que o dente não irrompido se adapte adequadamente, deve-se considerar que o folículo pericoronário dos caninos superiores tende a ser lateralmente mais bojudo e largo quando comparado com o dos demais dentes, em função da anatomia específica desse dente.

A medida do espaço na arcada dentária que ofereceria menores riscos de reabsorção radicular dos dentes vizinhos durante o tracionamento ortodôntico corresponderia a 1,5 vezes a distância mesiodistal do canino superior, muito embora essa medida nem sempre seja passível de aplicação em todos os casos clínicos. 
Nos próximos trabalhos, abordaremos as outras possiveis consequências do tracionamento ortodôntico de dentes não irrompidos, especialmente dos caninos superiores, entre as quais destacam-se a: (1) Reabsorção cervical externa nos caninos tracionados; (2) Anquilose alveolodentária do canino envolvido;
(3) Metamorfose cálcica da polpa e necrose pulpar asséptica.

O objetivo dessa abordagem está relacionado com a prevenção dessas possíveis consequências do tracionamento ortodôntico, visto que, em sua quase totalidade, podem ser evitadas se determinados cuidados técnicos forem adotados.

\section{REFERÊNCIAS}

1. Cahill DR, Marks SC Jr. Tooth eruption: evidence for the central role of the dental follicle. J Oral Pathol. 1980 Jul;9(4):189-200.

2. Consolaro A. Caracterização microscópica de folículos pericoronários de dentes não irrompidos e parcialmente irrompidos. Sua relação com a idade. [tese]. Bauru (SP): Universidade de São Paulo; 1987.

3. Consolaro A, Consolaro MFMO, Santamaria M Jr. A anquilose não é induzida pelo movimento ortodôntico. Os restos epiteliais de Malassez na fisiologia periodontal. Rev Clín Ortod Dental Press. 2010 abr-maio;9(2):101-10.
4. Damante JH. Estudo dos folículos pericoronários de dentes não irrompidos e parcialmente irrompidos. Inter-relação clínica, radiográfica e microscópica. [tese]. Bauru (SP): Universidade de São Paulo; 1987.

5. Ericson S, Kurol J. Radiographic examination of ectopically erupting maxillary canines. Am J Orthod Dentofacial Orthop. 1987 Jun;91(6):483-92.

6. Otto RL. Early and unusual incisor resorption due to impacted maxillary canines. Am J Orthod Dentofacial Orthop. 2003 Oct;124(4):446-9.
Endereço para correspondência

Alberto Consolaro

E-mail: consolaro@uol.com.br 